\title{
ENTRE RIMAS E MÉTRICAS: NO JOGO POÉTICO DA MATERIALIDADE SIGNIFICANTE DO CORDEL
}

\author{
FERNANDA MORAES D'OLIVO'
}

\author{
Faculdade de Ciências, Filosofia e Letras \\ Fundação Técnico-Educacional Souza Marques \\ Av. Ernani Cardoso, 335 - Cascadura, Rio de Janeiro - RJ, 21310-310
}

fernanda.dolivo@gmail.com

\begin{abstract}
Resumo. Neste artigo, busco compreender o modo de dizer do cordel, que se configura pelo poético, principalmente, pelo jogo entre rima e métrica que constituem o ritmo. Para o desenvolvimento das análises, serão importantes os trabalhos de Lagazzi, sobre a materialidade significante, as reflexões de Gadet \& Pêcheux (2004), Mariani (2007) e Almeida (2009, 2014) sobre a poesia da língua, $O$ corpus deste trabalho foi constituído por recortes de três folhetos: A morte de Bin Laden na Boca do Povo, de Antônio Barreto; Dilma Rousseff já é presidente da Nação, de Bule Bule e Usina de Belo Monte, de Nando Poeta. A partir das análises desses recortes, além de compreender a estrutura significante do cordel, também o compreendemos como um lugar discursivo de constituição do poeta-cordelista.
\end{abstract}

Palavras-chave: literatura de cordel; Análise de Discurso Materialista; poesia.

\begin{abstract}
Abrstract. This article aims to understand how the cordels speak, which is based on poetic, mainly, by the game between rhyme and metric that constitute the rhythm. For the development of the analyzes, the work of Lagazzi on the significant materiality, the reflections of Gadet \& Pêcheux (2004), Mariani (2007) and Almeida $(2009,2014)$ on the poetry of the language will be important. The corpus of this work was constituted by cuts of three cordels: A morte de Bin Laden na Boca do Povo, by Antônio Barreto; Dilma Rousseff já é presidente da Nação, by Bule Bule and Usina de Belo Monte, by Nando Poeta. From the analysis of these cuts, we do not only understand the significant structure of the cordel, but also understand it as a discursive place of the poet-cordelista constitution.
\end{abstract}

Keywords: cordel literature; Materialist Discourse Analysis; poetry.

\footnotetext{
${ }^{1}$ Professora Assistente I na Graduação e na Pós-Graduação (Letras) na Fundação Técnico-Educacional Souza Marques (FTESM/RJ).
} 


\section{INTRODUÇÃO}

[...] quando a emoção vem desarrumar a bela ordenação lógica da frase [...] 'constitui' um outro aspecto da mesma luta entre o sentimento impulsivo e desorganizador, e a arquitetura intelectual da linguagem [...].

Dauzat, Le génie de la langue française

Neste artigo, apresento recortes da reflexão sobre a escritura poética do/no ${ }^{2}$ cordel $^{3}$, realizada durante o meu percurso acadêmico e minhas pesquisas sobre a discursividade do folheto, tendo como base, principalmente, as considerações obtidas a partir do meu trabalho de doutorado, intitulado Narratividade e senso comum: nas rimas dos versos de cordel $^{4}$, e os desdobramentos posteriores a essa pesquisa.

As discussões que serão apresentadas aqui tratarão das especificidades da materialidade significante do cordel, sendo esta construída no e pelo poético da língua, pelo modo como o poeta brinca e joga com o significante para que a poesia de cordel seja configurada. Portanto, no jogo dessa materialidade, busco olhar para o modo de dizer do cordel, considerando a sua estrutura poética e o jogo entre rimas e métrica na produção do ritmo, para compreender como a sua materialidade significante se significa e produz sentidos. Para tal, serão de suma importância as considerações de Lagazzi (2004, 2009, 2011a, 2011b, 2012, 2013, 2014, 2015) sobre a materialidade significante, as reflexões de Gadet \& Pêcheux (2004) e Mariani (2007) sobre a poesia da língua, e Almeida (2009, 2014) sobre o funcionamento discursivo do poético na/da língua e sua relação com a ordem do discurso literário.

Para compreender como a materialidade significante do cordel, o seu modo de dizer, produz sentidos no poético, recorto trechos de folhetos cujas histórias narradas não estabelecem relação a não ser pela estrutura poética: A morte de Bin Laden na Boca do Povo, de Antônio Barreto (2011); Dilma Rousseff já é presidente da Nação, de Bule Bule (2011) e Usina de Belo Monte, de Nando Poeta (2011). É no entremeio das rimas, da métrica e no ritmo dos folhetos que as análises irão tomar corpo.

\footnotetext{
${ }^{2}$ Buscarei observar a poesia que é constitutiva do cordel, assim como esta funciona no cordel produzindo sentidos.

${ }^{3}$ Ao longo deste artigo, também será usado o nome de folheto para se referir as obras de poesia de cordel.

${ }^{4}$ Trabalho de doutorado realizado no Instituto de Estudos de Linguagem/Unicamp, sob orientação da Profa. Dra. Suzy Maria Lagazzi e financiado pela FAPESP.
} 


\section{SOBRE A MATERIALIDADE SIGNIFICANTE DA POESIA DE CORDEL: REFLEXÕES TEÓRICAS ${ }^{5}$}

A formulação materialidade significante, fundamental para a compreensão das questões deste artigo, foi proposta por Lagazzi a partir de um exercício analítico dos documentários Boca de Lixo e Teresa, e que tem consequências em inúmeros de seus trabalhos, como Lagazzi (2004, 2009, 2011a, 2011b, 2012, 2013, 2014, 2015). A autora define este conceito como

Uma deriva da definição de discurso como a relação entre a língua e a história, deriva com a qual pude concernir o trabalho com as diferentes materialidades e reiterar a importância de tomarmos o sentido como efeito de um trabalho simbólico sobre a cadeia significante, na história, compreendendo a materialidade como o modo significante pelo qual o sentido se formula. (LAGAZZI, 2011a, p. 313)

Considerar a primazia do significante sobre o significado é de extrema relevância para a compreensão do próprio termo materialidade significante. Chamo a atenção para a formulação final deste trecho: o modo significante pelo qual o sentido se formula. $\mathrm{O}$ sentido, desse modo, se formula na cadeia significante, ou nos termos de Lacan (1985, p.505 e 506, apud MARIANI, 2007), é onde o sentido insiste, produzindo um deslizamento do significado sob o significante, o que nos leva a considerar os elementos do significante sempre em relação $a$ - na produção dos sentidos (LAGAZZI, 2009).

$\mathrm{Na}$ reiteração da perspectiva materialista e do trabalho simbólico sobre o significante (LAGAZZI, 2011a), os sentidos se formulam em meio à materialidade significante o que, segundo Lagazzi (2012), possibilita considerar a diferença na relação constitutiva com o simbólico, diferença esta que se constitui na relação com a história.

Os poemas de cordel, entrecortados pelo poético, abrem espaço para um trabalho com sua materialidade significante no sentido de buscar compreender como os seus constituintes - ritmo, estereotipia, aspecto lúdico -, e a sua própria estrutura poética, funcionam na formulação dos sentidos. Almeida (2014), em seu artigo Narrativa em Cordel: uma relação entre literatura e religião, nos apresenta uma reflexão acerca do constante embate entre escrita e oralidade que configura e organiza, pelo poético, a escritura do cordel. Segundo a autora, há uma memória da oralidade, constitutiva da materialidade do cordel, a qual é recortada e organizada pelo modo poético. O cordel se configura, assim, por meio da sua estrutura poética fixa como sendo um organizador de sentidos.

Para que a poesia seja caracterizada como cordel, não basta apenas ter uma temática condizente com as dos folhetos tradicionais e ser considerada como poesia popular. Como já dito, é preciso seguir uma certa estrutura que garanta um ritmo no modo de dizer/cantar a poesia que traga à tona a memória da oralidade. Os folhetos, geralmente, são organizados em versos de sete sílabas métricas com estrofes de seis ou sete versos, com um esquema de rima estabilizado ao longo das estrofes, conforme o exemplo abaixo:

\footnotetext{
${ }^{5}$ Este trecho é baseado em parte das reflexões apresentadas no primeiro capítulo da minha tese de doutorado.
} 
O sujeito preguiçoso (A)

Depois que aprende a roubar (B)

Não tem jeito que dê jeito $(\boldsymbol{C})$

Nunca mais quer trabalhar (B)

E se o cabra for estudado (D)

Ninguém pode segurar. (B)

O Brasil já conheceu (A)

Um tal de P.C. Farias (B)

Que desde cedo, na escola (C)

Promete que enricaria (B)

Que, quando fosse um doutor (D)

Muitos milhões roubaria. (B)

\section{(Trecho extraído do cordel 0 dia em que P.C. Farias infernizou o inferno, de Vicente Campo Filho)}

O esquema de rima apresentado acima (ABCBDB) é repetido ao longo das estrofes, constituídas por versos de sete sílabas métricas. Repetem-se as estruturas, o que as torna fixa, estabilizadas. Os próprios poetas cantam em seus versos sobre essa estruturação fixa do poema, como é possível observar nos seguintes versos presentes no folheto Cordel Novo \& Velho ${ }^{6}$, o qual é considero um metacordel por trazer, em seu conteúdo organizado pela poesia, dizeres sobre o cordel e como ele deve ser estruturado, ser elaborado. Seria, nesse sentido, o próprio cordel falando dele mesmo por meio da sua poética:

- O cordel velho foi escrito/ com talento e galhardia,/rima, métrica, oração,/como exige a poesia,/num brilhantismo perfeito/ pois tudo isso era feito/sem quase tecnologia. (Raul Poeta)

- "Cordel Velho" e "Cordel Novo"/ Não consigo dividir/pois o que agrada ao povo/ é o modo de transmitir/tendo rima e oração/fiel metrificação/dá gosto ler e ouvir. (Josenir Alves de Lacerda)

- A rima metrificada/do nosso velho Cordel/ regula o cordel novo/ quando passa pro papel/ avançamos pro futuro/ sendo ao passado fiel. (Willian J.G. Pinto)

Destaco, nesse recorte, os trechos nos quais os poetas chamam atenção para o modo como deve ser a escrita do cordel. A repetição constante de palavras como rima, métrica, oração; fiel metrificação, rima metrificada marca, no discurso do metacordel, a relevância desses elementos para a constituição e caracterização do folheto. No metacordel, rimas e métrica não são apenas palavras no conteúdo do folheto, mas tomam corpo na sua estrutura, dando forma ao folheto e ao seu modo de organização, dando gosto de lê-la e ouvi-la.

O ritual da escrita e organização do/no cordel configura um espaço já estabelecido, já-dado, para o trabalho dos cordelistas com o significante; é um espaço que cerceia o sujeito poeta e regula o seu modo de jogar e brincar com as palavras, com os sentidos. A ruptura desse espaço, se, por um lado, poderia permitir uma maior liberdade de

\footnotetext{
${ }^{6}$ O folheto "Cordel: Novo \& Velho" é constituído em um processo de escrita colaborativa e cada estrofe é escrita por um cordelista.
} 
formulação ao autor, por outro, pode acarretar o menor interesse do público, caso comprometa o processo de recitação.

É preciso, assim, considerar o texto do cordel juntamente com a musicalidade produzida pelo ritmo que, por sua vez, é configurado nesse espaço já-dado de criação do poeta. Texto e ritmo devem ser olhados como materialidades imbricadas umas nas outras, em uma relação de composição, nos termos de Lagazzi (2009):

O batimento estrutura/acontecimento referido a um objeto simbólico materialmente heterogêneo, requer que a compreensão do acontecimento discursivo seja buscada a partir das estruturas materiais distintas em composição. Realço o termo composição para distingui-lo de complementariedade. Não temos materialidades que se complementam, mas que se relacionam pela contradição, cada uma fazendo trabalhar a incompletude na outra. Ou seja, a imbricação material se dá pela incompletude constitutiva da linguagem, em suas diferentes formas materiais. Na remissão de uma materialidade a outra, a não-saturação funcionando na interpretação permite que novos sentidos sejam reclamados, num movimento de constante demanda. (LAGAZZI, 2009, p. 69)

O ritmo, proporcionado pela relação entre rima e métrica, faz trabalhar a incompletude da escrita trazendo, fortemente, o embate com a oralidade e, no acontecimento da recitação do cordel, texto e ritmo se imbricam significando o modo de organização e o ritual de escritura poética do cordel. Desse modo, o jogo de palavras, a cadência dos versos, a construção e organização do discurso poético em versos e estrofes constroem um outro modo de falar, constituído e significado pelo movimento produzido entre o significante e a poesia que há na língua. Produz-se, assim, um outro modo de dizer na cadeia de significantes, que, segundo Mariani (2007),

Em suma, a emergência de um dizer outro pode se dar por via de associações de sentido e/ou de forma e/ou de som, fazendo o sujeito falar (ou escrever, ou ler, ou ouvir ou compreender) aquilo que não esperava falar (ou escrever, ou ler, ou ouvir ou compreender). Mas, ao lado desse processo, há outros inscritos na própria sincronicidade da cadeia significante, provocando um desencadeamento/reencadeamento no momento mesmo de sua enunciação. Ou seja, é na própria massa acústica que se desenrola essa possibilidade infinita dos deslizamentos e, por consequência, dos processos de produção de sentidos outros. (MARIANI, 2007, p. 8)

De Lemos (2009), em seu artigo Poética e Significante, escrito para uma palestra cuja plateia era formada tanto por linguistas quanto por psicanalistas, faz uma afirmação forte e extremamente relevante sobre o funcionamento do poético no discurso: a autora afirma que a poesia é feita na ruptura do discurso ordinário (DE LEMOS, 2009, p. 208), ou seja, do nosso falar cotidiano, constituído de forma coesa e coerente, conforme objetiva a prosa. As formulações do discurso ordinário estariam sob o efeito da transparência e evidência imaginária, não produzindo um jogo com o significante. No discurso poético, porém, no jogo entre significado e significante, a poesia diz uma coisa e significa outra (RIFATERRE, 1978 apud DE LEMOS, 2009), rompendo com o ordinário dos sentidos. Complementando esta afirmação de Rifaterre, cito Campos (2013, 
p. 158), que afirma que "o poeta e o artista convidam a subverter o que a palavra faz ver de incessante, fazendo ver pelo poema, pela pintura e pela fotografia o que havia de intangível e que parecia ausente". É aí, nesse fazer ver o que é intangível que a poesia e os sentidos produzidos/provocados por ela significam outra coisa, fugindo do corriqueiro. $\mathrm{Na}$ poesia há, portanto, uma outra configuração dos dizeres, um outro movimento produzido por outros procedimentos que determinam certos arranjos com o significante que dão corpo aos sentidos (ALMEIDA, 2014), constituindo, desse modo, uma outra tecetura $^{7}$ (NECKEL, 2010) no fio do discurso pelo funcionamento da materialidade discursiva do poético na sua imbricação com o significante. Uma tecetura estabelecida na e pela ordem do poético, que, no cordel, traz a memória da oralidade para o texto. Sobre essa ordem do poético, GADET \& PÊCHEUX (2004), em consideração aos trabalhos de Saussure com os anagramas, afirmam que

Diante das teorias que isolam o poético do conjunto da linguagem, como lugar de efeitos especiais, o trabalho de Saussure (tal como ele é, por exemplo, comentado por Starobinski) faz do poético um deslizamento inerente a toda linguagem: o que Saussure estabeleceu não é uma propriedade do verso saturnino, nem mesmo da poesia, mas uma propriedade da língua própria. $\mathrm{O}$ poeta seria apenas aquele que consegue levar essa propriedade da linguagem a seus últimos limites; ele é, segundo a palavra de Baudrillar, suprimindo a acidez, um "acelerador de partículas da linguagem". Poder-se-ia assim dizer, no espírito do comentário de Lacan sobre a fórmula "não há pequenas economias": "não há linguagem poética". (GADET \& PÊCHEUX, 2004, p. 58)

A poesia ${ }^{8}$, desse modo, faz parte da própria ordem da língua, constituída no equívoco, na falha e nos deslizamentos de sentidos. Para Milner (1982) "nada da poesia é estranho à língua e nenhuma língua pode ser pensada completamente, se aí não se integra a possibilidade de sua poesia" (p.332), o que reafirma que o poético é intrínseco à língua, constituindo sentidos. É, portanto, na materialidade significante que a poesia produz seus procedimentos artísticos (ALMEIDA, 2009, p. 3).

A poesia de cordel, desse modo, necessita ser declamada, ouvida e não apenas lida em silêncio para que a composição texto e musicalidade/ritmo aconteça. Essa é, na verdade, uma necessidade de toda poesia, pois é no ato de declamar que podemos observar uma união, constitutiva, entre som e sentido. ${ }^{9}$ Nos estudos acadêmicos sobre a poesia, diversos pesquisadores, como Pillar (1983) e Goldstein (2006) reafirmam a

\footnotetext{
${ }^{7}$ Neste trabalho, usamos o termo tecetura, conforme Neckel (2010) o define em seu trabalho de doutorado. A autora diferencia os termos tecetura e tessitura: "Tomamos por tecetura, o tecer dos dizeres no fio do discurso, na trama dos sentidos, no jogo polissêmico e no interdiscurso. E, tomamos por tessitura, o funcionamento próprio da materialidade discursiva em sua estrutura, na forma material ou, na imbricação com o significante" (p. 107).

${ }^{8}$ É importante salientar que poema e poesia não devem ser tomados como sinônimos. Segundo Lyra (1986), "se o poema é um objeto empírico e se a poesia é uma substância imaterial, é que o primeiro tem uma existência concreta e a segunda não. Ou seja, o poema, depois de criado, existe por si, ao alcance de qualquer leitor, mas a poesia só existe em outro ser: primeiramente, naquele onde ela se encrava e se manifesta de modo originário, oferecendo-se à percepção objetiva de qualquer indivíduo, secundariamente no espírito do indivíduo que a capta desses seres e tenta (ou não) objetivá-la num poema, terciariamente, no próprio poema resultante desse trabalho objetivador do indivíduo-poeta" (p. 6).

${ }^{9}$ Segundo Paz (1997, p. 102), o poema é um organismo verbal, rítmico, um objeto de palavras ditas e ouvidas, não descritas nem lidas.
} 
importância de se considerar a cadência e o ritmo na interpretação de um poema, não ficando apenas restrito à sua materialidade verbal e ao conteúdo. É preciso, nesse sentido, levar em conta a materialidade significante poética que toma forma e se materializa no momento da declamação.

Retomo aqui alguns aspectos acerca da discursividade do cordel compreendidos na iniciação científica ${ }^{10}$ e reafirmados no trabalho de mestrado ${ }^{11}$, que serão importantes para o aprofundamento da compreensão sobre a sua materialidade significante do cordel. Durante minha pesquisa de iniciação científica, cujo objetivo era compreender como se dava a produção e circulação do sentido sobre as mulheres na literatura de cordel, o ritmo, produzido pelo jogo entre rimas e métrica, e a estereotipia foram relevantes para a compreensão do modo como determinadas formulações sobre a figura da mulher circulavam em meio ao discurso do cordel.

Os estereótipos que se opunham ao conceito de mulher ideal, os quais eram sustentados por pré-construídos morais, eram apresentados no folheto de forma exagerada: a mulher-macho em oposição à mulher delicada; a mulher coroa em oposição à mulher casada e a prostituta em oposição à mulher considerada "certinha". Esses estereótipos são textualizados no cordel em meio ao deboche que, pela sua cadência, pela sua musicalidade e humor, os significa em meio à brincadeira. Podemos considerar que a discursividade que circula nos folhetos produz um determinado efeito de sentido nos interlocutores. Esse efeito é resultado do entrecruzamento entre ritmo e formulações estereotipadas, o que produz um efeito de ludicidade na discursividade do cordel. Desse modo, no jogo do significante, organizado pela escritura poética, sentidos outros são configurados na tecetura do discurso do cordel.

$\mathrm{Na}$ organização do significante pelo cordel e no seu modo de dizer, há a construção de uma linearidade, de uma coesão a partir da relação entre os versos e entre as estrofes, que, pela própria estrutura poética, são recortados por movimentos de elipse, termo usado por Haroche (1984) em suas reflexões sobre aspectos discursivos da gramática. Segundo a autora, a elipse, juntamente com a incisa:

constituiriam então a forma com que a teoria das associações joga na teoria dos sintagmas. Pode-se, portanto, perguntar se a questão da completude postulada na gramática se prende necessariamente à ideia de modelo da língua, sob a forma de "figuras" provisórias (sem dúvida) e parciais (certamente) de completude. É desenvolvendo as relações entre língua e subjetividade, sobre a questão da determinação, que poderíamos talvez aprender o que é preciso entender por completude na gramática. (HAROCHE, 1984, p. 135)

Faço um deslocamento, necessário, para pensar a elipse em meio ao poético. No jogo rítmico produzido no cordel, versos se ligam a outros versos e estrofes se conectam a outras estrofes por meio de uma falta necessária, de uma coesão elíptica, que coloca em evidência a incompletude da linguagem, para que, então, o ritmo possa produzir esse

\footnotetext{
${ }^{10}$ As compreensões da minha pesquisa de iniciação científica estão publicadas no artigo "No entremeio do funcionamento do discurso do cordel: o ritmo e a estereotipia". Língua e Literatura, vol. 27, FFLCH, 2010, escrito em coautoria com Suzy Maria Lagazzi, orientadora do meu trabalho de iniciação científica.

${ }^{11}$ D’OLIVO, F.M. O social no cordel: uma análise discursiva. Dissertação de Mestrado. Universidade Estadual de Campinas, IEL, Campinas, 2010.
} 
efeito de linearidade e de completude no encadeamento dos dizeres do folheto. Essa necessidade de linearidade e completude opõe-se a elipse, que segundo Haroche (op. cit.), rompe com o desenrolar do discurso, mostrando-nos que os discursos presentes nos folhetos são formulados e organizados em meio à contradição.

O ritual da escritura poética, esse imbricar entre texto e ritmo que dá linearidade e, ao mesmo tempo, rompe com o desenrolar do discurso vai dando corpo ao cordel e ao seu modo de organizar o dizer, sempre no jogo com o significante. Na sessão seguinte, após essas considerações teóricas sobre a poesia e o modo de dizer do cordel, vamos observar, no procedimento analítico, como se dá o funcionamento do poético na estrutura dos folhetos.

\section{NO JOGO DA ESCRITURA POÉTICA DO CORDEL}

O modo como a língua se estrutura, segundo Payer (2006), supõe uma memória na repetição das palavras, dos fonemas, da sintaxe. Essa memória da e na língua se repete na forma estruturante do cordel: há uma repetição, em cada estrofe, de esquemas de rimas e métricas, que reafirma a memória da oralidade constitutiva do cordel. É essa repetição que será objeto de nossas análises para compreender o funcionamento da materialidade do cordel na formulação dos sentidos.

Os folhetos selecionados, como já dito, apresentam temas variados, pois o que é importante para a análise, é o modo como o cordel organiza os sentidos pelo poético. $\mathrm{O}$ folheto $A$ morte de Bin Laden na boca do povo apresenta a opinião de pessoas a respeito da morte de Bin Laden e das atitudes tomadas pelo então presidente dos Estados Unidos, Barack Obama, em relação à sua morte. Já em Dilma Rousseff já é presidenta da nação, fala-se das qualidades da presidente Dilma Rousseff como mulher e política. Esse folheto apresenta um tom de ode à presidenta, repleto de elogios, o que reafirma a posição política do cordelista. No folheto Usina de Belo Monte, vemos, em seus versos, críticas a respeito da construção da Usina de Belo Monte no norte do Brasil. Segundo os dizeres presentes no cordel, essa usina irá destruir a mata, o ambiente dos índios e provocará um desastre ambiental. $\mathrm{O}$ primeiro e terceiro folhetos foram encontrados na Internet, não havendo exemplar impresso. Já o segundo, circula apenas no modo impresso. Apesar dessa diferença no modo de circulação, a estrutura de rima e métricas ainda é regular nos três folhetos. Abaixo trago as três primeiras estrofes que constituem o recorte; na lateral de cada verso, há a marcação do esquema de rimas, fundamental para a análise que se seguirá. 


\section{A MORTE DE BIN LADEN NA BOCA DO POVO}

Antonio Barreto, 2011.

O suposto assassinato $(\boldsymbol{A})$

Ordenado por Obama (B)

Aniquilando de vez (C)

O seu ex-parceiro Osama (B)

Caiu na boca do povo (D)

Que este cordel proclama. (B)

Quando Obama anunciou (A)

Tal fato no Paquistão (B)

Peguei caneta e papel $(\boldsymbol{C})$

Pra colher a opinião (B)

Do povo de Salvador (D)

E cordelizar, então. (B)

Sem nenhuma acanhação $(\boldsymbol{A})$

Eu pude aqui registrar $(\boldsymbol{B})$

Neste singelo cordel $(\boldsymbol{C})$

Da cultura popular (B)

$A$ voz do povo, nas ruas, (D)

Conforme vou the mostrar: (B)

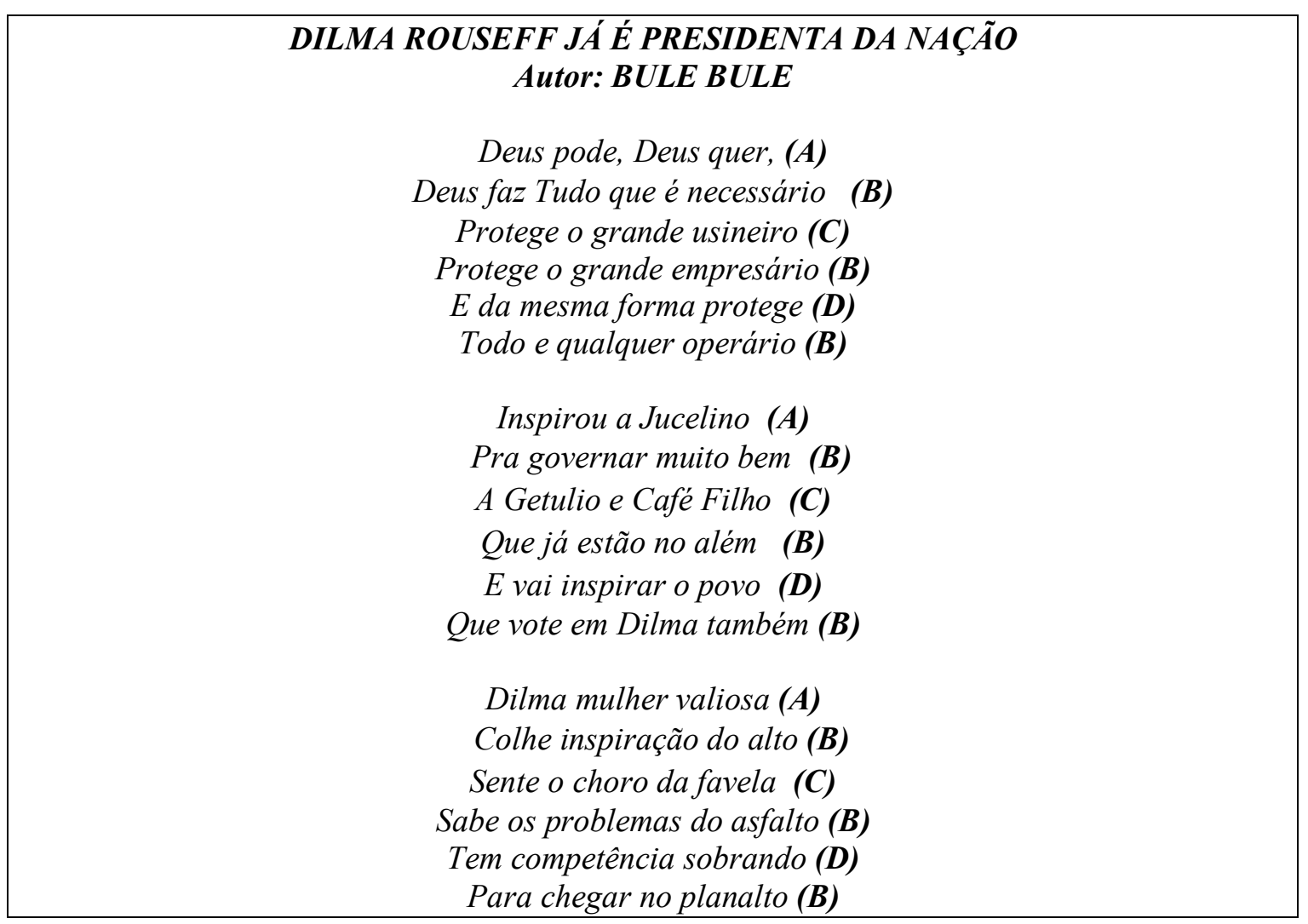




\section{Usina de Belo Monte \\ De Nando Poeta}

No crime de Belo Monte (A)

Lula puxou o gatilho (B)

Do Xingu tira seu brilho (B)

Veneno joga na fonte $(\boldsymbol{C})$

Ofuscando o horizonte (C)

Um presente para empresa (D)

Que mata a natureza (D)

E povos dessa floresta (E)

Pancada leva na testa (E)

Bioma não tem defesa. (D)

Não bastasse o São Francisco (A)

Com sua transposição (B)

Exército de arma em mão (B)

Impondo a força o confisco (C)

$O$ rio caindo em risco $(\boldsymbol{C})$

$E$ vida de pescadores (D)

Sem peixe, água, e com dores (D)

Florestas sendo alugadas (E)

Por gringos são devastadas (E)

Os seus fies predadores. (D)

Os indios do rio Xingu (A)

Perderão pesca e a caça (B)

Jogados vão à desgraça (B)

Não come mais o pitu $(\boldsymbol{C})$

Também não tem o tatu (C)

Ficando sem o alimento (D)

É pleno seu sofrimento (D)

Moradores da floresta (E)

Que não cala, mas contesta (E)

Tem força seu argumento. (D)

As estrofes acima são exemplares do modo de estruturação dos folhetos selecionados. Elas são constituídas por versos de sete sílabas métricas, sendo que o primeiro e o segundo apresentam seis versos em cada estrofe, cujo esquema de rimas segue a organização ABCBDB. Já o último cordel, apresenta estrofes mais longas, formadas por dez versos, com o seguinte esquema de rimas: ABBCCDDEED. Nessa regularidade, que toma corpo ao longo dos folhetos, o ritmo se institui como constituinte do cordel. É uma regularidade que se sustenta na e pela memória da estrutura do cordel, da repetição fonêmica de rimas e significa o folheto enquanto um ritual de linguagem ${ }^{12}$, que organiza os sentidos de forma própria, pelo poético, dando gosto de ler e ouvir o cordel.

\footnotetext{
${ }^{12}$ Agradeço a Profa. Dra. Eliana de Almeida que, durante a arguição da minha defesa de doutorado, chamou a atenção para o Cordel enquanto um ritual de linguagem, o que colaborou para o desenvolvimento das análises que aqui apresento.
} 
Pelo ritmo, as temáticas são textualizadas e a partir dele, confere-se um outro modo de significar os assuntos. Há um jogo de brincadeira conferida pelo modo poético do cordel, em que, para seguir determinado esquema é preciso selecionar determinadas palavras, excluindo outras, silenciando outras possibilidades. O ritmo, assim, se instaura, no discurso, como um acontecimento que se dá ali, naquela possibilidade de dizer, naquele instante, por um determinado jogo de rima e métrica que, para existir, silencia outros dizeres e outras organizações sintáticas.

No esquema de rimas do primeiro e do segundo folheto, o segundo, quarto e sexto versos obrigatoriamente rimam. A estrofe inicial, por exemplo, do cordel sobre Osama Bin Laden, apresenta rimas em ama (Osama; Obama; proclama), a do folheto Dilma Rousseff já é presidenta da nação apresenta rimas em ário (necessário, empresário, operário) e o folheto sobre a construção de Belo Monte traz um esquema de rima em que, necessariamente, o terceiro verso deve rimar com o segundo, o quinto com o quarto, o décimo como o sétimo e sexto versos e o nono com o oitavo. Esse modo de organizar o dizer regula as escolhas lexicais do cordelista, produzindo o movimento de cerceamento do sujeito na sua produção escrita, conforme mencionado no início deste artigo. Tanto as escolhas lexicais, quanto a organização sintática são reguladas pelo ritual do cordel, ritual este que exige tal organização para trazer a memória da oralidade, marcada aqui pelo ritmo. O ritmo, além de discursivizar os dizeres no cordel, também é importante para o processo de memorização dos mesmos pelo público leitor. Sobre o processo de memorização, Abreu (1999) diz que

saber, por exemplo, que o segundo, quarto e sexto versos terminarão com um mesmo som permite prever minimamente o que será dito e auxilia a recordação de uma história já conhecida. A regularidade fornece marcas, 'pistas', sobre o caminho que a composição seguirá, não só com que a apresenta, mas também para quem a ouve. (ABREU, 1999, p. 88)

Chamo a atenção para a parte final deste trecho. Essas marcas, pistas que o cordel nos dá é próprio da sua materialidade significante, a qual, como já dito, organiza os sentidos, textualiza o discurso em meio às rimas, jogos fônicos, que trazem à tona a própria memória discursiva da língua. Essa regularidade estrutural dos folhetos é fundamental para a circulação e memorização de suas histórias, contribuindo também para a preservação da sua tradição oral, pois a oralidade, conforme já tido, se materializa na forma de ritmo, com uma cadência própria e característica dessa poesia.

Hans Ulrich Gumbrecht, em sua aula inaugural na UFF, traz as reflexões do filósofo alemão Edmund Husserl, o qual afirma que o ritmo é um fenômeno que se produz na articulação com o tempo ${ }^{13}$. Desse modo, o processo de recitação do cordel é um objeto temporal, que apresenta um movimento configurado no retorno constante às mesmas estruturas de rima e de métrica, a jogos de palavras, de sons, que se repetem. É um movimento de um constante retorno ao mesmo. Há aí o funcionamento de uma memória que marca esse ritual de linguagem do cordel. Dos recortes apresentados, os esquemas de rimas estruturados em ABCBDB e ABBCCDDEED, os versos organizados em sete sílabas métricas textualizam uma determinada forma de se falar sobre política e Dilma Rousseff, sobre Bin Laden, terrorismo e imperialismo americano e sobre os problemas

\footnotetext{
${ }^{13}$ Palestra conferida pelo professor Hans Ulrich Gumbrecht "Teoria da prosódia na poesia”, na UFF.
} 
causados pela construção da Usina de Belo Monte. São assuntos do cotidiano narrados dentro de uma estrutura que proporciona um determinado jogo de linguagem que confere sentidos outros à discursividade desses assuntos; sentidos que se aproximam do lúdico, produzido pelo poético.

O ritmo também dá a coesão aos dizeres presentes nos recortes. A elipse necessária apaga no discurso do cordel marcadores argumentativos ${ }^{14}$, pronomes relativos que, ao serem postos em evidencia, mostram-nos sentidos outros nas tramas dos versos de cordel. Porém, no processo de trazer à tona os termos que antes estavam elípticos, apaga-se a estrutura fixa do cordel, mas não apaga a poesia que há na sua discursividade. Vejamos.

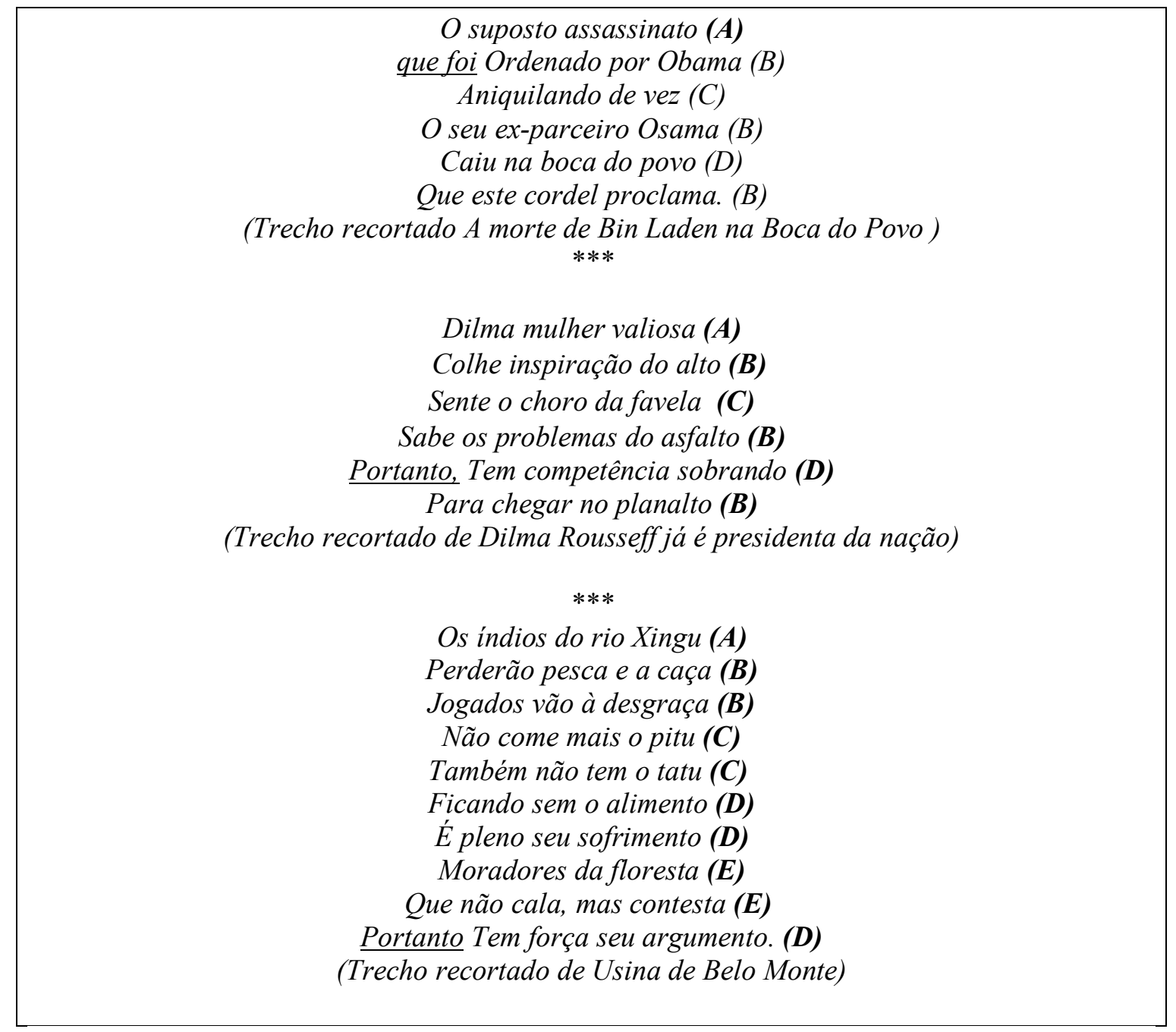

As palavras sublinhadas foram inseridas no entremeio do discurso do cordel quebrando o ritmo, porém, enfatizando o encadeamento coesivo. Ao acrescentar o pronome relativo e a conjunção portanto nos versos, vemos, no primeiro, uma progressão, já sustentada pela coesão elíptica proporcionada pelo ritmo, e nos dois últimos,

14 As análises sobre o funcionamento dos marcadores argumentativos na produção de sentidos na discursividade do cordel estão desenvolvidas em minha tese de doutorado Narratividade e Senso Comum: nas rimas dos versos de cordel. 
observamos uma progressão argumentativa, a qual nos conduz a determinados sentidos, mas que não é explícita no folheto - a relação de implicatura é silenciada pelo modo coesivo proporcionado pelo ritmo. Apesar de haver o silenciamento das relações de implicatura, ainda há marcas que mostram a força argumentativa do cordel, assim como a sua narrativa, justamente pelo modo como os versos são encadeados para produzir o movimento rítmico por meio do jogo de rimas. Desse modo, a estrutura do cordel, que traz à tona memórias de dizer, memórias da oralidade proporcionada pelo acontecimento do ritmo no processo de recitação, traz, nas tramas dos seus versos, um modo narrativo e argumentativo, que se constituem no processo de coesão elíptica, específica da escritura poética.

Não é necessário, pois, que se apresentem todos os termos para que haja a constituição da argumentação e da narrativa. Elas já estão formuladas na poesia que há na língua, estruturada e organizada pelo cordel. No batimento entre a memória da escrita e da oralidade que se dão no cordel, o poeta joga com o significante, dentro de uma estrutura já-dada, para organizar e estruturar a sua relação com o exterior. O cordel, assim, se configura como um ritual de linguagem que traz em sua materialidade repetições necessárias para a formulação do dizer e produção dos sentidos.

\section{PARA EFEITO DE FECHAMENTO}

Neste artigo, busquei apresentar algumas de minhas reflexões acerca da materialidade significante do cordel, o seu modo de produzir sentidos, de organizá-los pelo poético. Provocações foram lançadas às reflexões teóricas e analíticas para discutir o estatuto do cordel enquanto um ritual de linguagem ao estruturar, por meio de uma estrutura fixa, os significantes em meio às rimas e métricas, que, por sua vez, produzem um movimento rítmico aos dizeres do cordel.

Na ordem da escritura poética do cordel já se configura uma historicidade a partir da sua materialidade que traz uma memória, um retorno ao mesmo devido à repetição da estrutura métrica em cada verso e à repetição do esquema de rimas em cada estrofe, as quais, ao longo de todo o poema, são compostas pelo mesmo número de versos. Nesse jogo produzido pela repetição, é possível observar a memória da oralidade configurada no ritmo constituído nas tramas dos versos de cordel. Ritmo que produz um efeito de coesão, de unidade à poesia, possibilitando uma progressão discursiva à história narrada no cordel, aos dizeres do poeta.

Segundo Almeida (2009), o poeta, na sua posição sujeito-escritor, se posiciona $n a$ poesia e não somente diante da temática que discute. Nesse sentido, a cadeia significante do cordel, constituída no/pelo jogo de rimas e métricas bem marcadas, organiza a relação língua/sujeito/mundo, e nessa organização, marcada pelo poético, pela memória da oralidade, configura-se o sujeito poeta-cordelista. 


\section{REFERÊNCIAS}

ABREU, M. Histórias de cordéis e folhetos. Campinas: Ed. Mercado das Letras, 1999.

ALMEIDA, E. Narrativa em Cordel: uma relação entre Literatura e Religião. Em: FERREIRA, A.M.; CASTRILLON-MENDES, O.M.; MAQUÊA, V. (Orgs.). Literatura, tradição, religiosidades. Cáceres: UNEMAT, 2014. v. 1, p. 101-112.

Poesia: a arte da língua. Em: Linguagem e História: múltiplos territórios. Campinas: RG, 2009.

CAMPOS, L.J. Olhar e imagem: construções basculares do sujeito na cultura. Em: INDURKY, F., FERREIRA, M.C.L., MITTMANN, S. (Orgs) O acontecimento do Discurso no Brasil. Campinas: Mercado das Letras, 2013.

CAMPOS FILHO, V. O dia em que P.C. Farias infernizou o inferno. s/n.

DE LEMOS, C.T.G. Poética e significante. Letras \& Letras, 25, vol. 1, 207-218, jan/jun 2009.

D'OLIVO, F.M.; LAGAZZI, S. No entremeio do funcionamento do discurso do cordel: o ritmo e a estereotipia. Língua e Literatura, vol. 27, FFLCH, 2010.

D’OLIVO, F.M. O social no cordel: uma análise discursiva. Dissertação. Mestrado em Linguística. Universidade Estadual de Campinas, IEL, Campinas, 2010.

GADET, F.; PECCHEUX, M. A língua inatingível: o discurso da história da linguística. Campinas: Ed. Pontes, 2004.

GOLDSTEIN, N. Versos, sons, ritmos. Séries Princípios. São Paulo: Ática, 2006.

GUMBRECHT, H. U. Teoria da prosódia na poesia. Palestra conferida na Universidade Federal Fluminense. Disponível em http://www.lis.uff.br/palestras-de-hans-ulrichgumbrecht-stanford-university-teoria-da-prosodia-na-poesia. Acesso em 14/02/2016.

HAROCHE, C. Fazer dizer, querer dizer. São Paulo: Hucitec, 1984.

LAGAZZI, S. Imagem e(m) Discurso: a formação das modalidades enunciativas. Em: TASSO, I.; CAMPOS, J. (OrgS.). A imagem em curso. A memória em pauta. Campinas: Pontes, 2015. v. 8, p. 51-66.

- Metaforizações metonímicas do social. ORLANDI, E. (Org.). Linguagem, sociedade, políticas. Pouso Alegre: UNIVÁS; Campinas: RG, 2014a. p.105-112.

. Um lugar à margem, quase invisível. Línguas e Instrumentos Linguísticos, Universidade Estadual de Campina, Pontes, julho/dezembro 2014b.

Quando os espaços se fecham para o equívoco. RUA [on-line], Edição Especial, Portal Labeurb, 2014c. http://www.labeurb.unicamp.br/rua 
Delimitações, inversões, deslocamentos em torno do Anexo 3. Em: LAGAZZI, S.; ROMUALDO, E.C.; TASSO, I. (Orgs.). Estudos do texto e do discurso. O discurso em contrapontos: Foucault, Maingueneau, Pêcheux. São Carlos: Pedro \& João, 2013a. p. 311-331.

. A imagem do corpo no foco da metáfora e da metonímia. REDISCO, v. 2, n. 1, 104-110, Vitória da Conquista, Edições UESB, jan./jun. $2013 b$.

O discurso em diferentes territórios: o vermelho entre todas as cores. Em: MalufSouza, O.; SILVA, V.; ALMEIDA, E. de; BISINOTO, L.S.J. (Orgs.). Discurso, Sujeito e Memória. Campinas: Pontes, 2012. p.133-146.

. Análise de Discurso: a materialidade significante na História. Em: DI RENzo, A.; MOTTA, A.L.A.R. da; OLIVEIRA, T.P. de (Orgs.). Linguagem, História e Memória: discursos em movimento. Campinas: Pontes, 2011a. p.275-290.

A materialidade significante em análise. Em: TFOUNI, L.V.; MONTE-SERRAT, D.M.; CHIARETTI, P. (Orgs.). A análise do discurso e suas interfaces. São Carlos: Pedro \& João, 2011b. p. 311-324.

O Recorte e o Entremeio: condições para a materialidade significante. Em: RODRIGUES, E.A.; SANTOS, G.L. dos; BRANCO, L.K.A.C.Branco (Orgs.). Análise de Discurso no Brasil: pensando o impensado sempre. Uma homenagem a Eni Orlandi. Campinas: RG, 2011c. p. 401-410.

O recorte significante na memória. Apresentação no III SEAD - Seminário de Estudos em Análise do Discurso, UFRGS, Porto Alegre, 2007. Em: INDURSKY, F. et. al. (Orgs.) $O$ discurso na contemporaneidade: materialidades e fronteiras. São Carlos: Claraluz, 2009. p.67-78.

LYRA, Pedro. Conceito de poesia. São Paulo: Ática, 1986. Série Princípios.

MARIANI, B.S.C. Silêncio e metáfora, algo para se pensar. Trama, Cascavel, v. 03, p. 55-71, 2007.

NECKEL, N.R.N. Tessitura e tecedura: movimentos de compreensão do discurso artístico no audiovisual. Tese. Doutorado em Linguística. Departamento de Estudos da Linguagem, Unicamp, 2010.

PILLAR, A. (Org.) A educação de olhar no ensino de artes. Porto Alegre: Mediação, 1983. 
Artigo recebido em: dezembro de 2017.

Aprovado e revisado em: abril de 2018.

Publicado em: maio de 2018.

\section{Para citar este texto:}

D’OLIVO, Fernanda Moraes. Entre rimas e métricas: no jogo poético da materialidade significante do cordel. Entremeios [Revista de Estudos do Discurso, ISSN 2179-3514, on-line, www.entremeios.inf.br], Seção Temática [Discurso, arte e literatura - Parte I], Programa de Pós-Graduação em Ciências da Linguagem (PPGCL), Universidade do Vale do Sapucaí (UNIVÁS), Pouso Alegre (MG), vol. 16, p. 327-342, jan. - jun. 2018.

DOI: http://dx.doi.org/10.20337/ISSN2179-3514revistaENTREMEIOSvol16pagina327a342 